\title{
The Bonding of Interstitial Hydrogen in the NiTi Intermetallic Compound
}

\author{
Dae-Bok Kang \\ Department of Chemistry, Kyungsumg Universin. Busan 608-736. Korea. E-mail: dbkangiâstar.ks.ac.kr \\ Received September 25, 2006
}

The interstitial hydrogen bonding in NiTi solid and its effect on the metal-to-metal bond is investigated by means of the EH tight-binding method. Electronic structures of octahedral clusters $\mathrm{Ti}_{4} \mathrm{Ni}_{2}$ with and without hydrogen in their centers are also calculated using the cluster model. The metal $\mathrm{d}$ states that interact with $\mathrm{H}$ is are mainly metal-metal bonding. The metal-metal bond strength is dininished as the new metal-hydrogen bond is formed. The causes of this bond weakening are analyzed in detail.

Key Words : Metal hydrides. Electronic stnicture. Bonding

\section{Introduction}

The intermetallic compound NiTi, which is the prototype of alloys exhibiting a shape memory behavior, is intensively studied over the world. ${ }^{1}$ Apart from the shape memory phenomenon, this type of alloy is of scientific and technological interest in view of the great potential for practical applications such as hydrogen storage media for fuel cells. electrodes for rechargeable batteries. and energy conversion materials. ${ }^{--4}$ This compound may be utilized as one of promising hydrogen storage materials for the development of a future clean energy system because it absorbs hydrogen readily under convenient conditions of pressure and temperature and forms a hydride.

Structural studies of hydrides of NiTi have been initiated by Noreus et $a l^{5}$ More recently, the structure of the hydrides $\mathrm{NiTiH}_{\mathrm{x}}(\mathrm{x}=1.0$ and 1.4$)$ has been resolved, including hydrogen positions, from powder neutron diffraction data. ${ }^{6}$ The results of these structural investigations established the existence of a tetragonal metal atom structure corresponding to the space group $14 / \mathrm{mmm}$ and led us to undertake a theoretical investigation of the electronic structure of $\mathrm{NiTiH}$ which was compared with that of the pure internetallic compound NiTi.

There are several papers related to the electronic structure of $\mathrm{NiTi}^{7.11}$ However. the study of hydrogen interaction with NiTi alloy is rather scarce. The lack of such investigations is probably due to the very poor understanding of the positions of hydrogen atoms in the hydrides. The investigation of the band structure for hydrogenated NiTi is important to reveal the origin of chenical bonding in NiTi alloy and its interaction with $\mathrm{H}$ as an impurity in the extended structure. In the present work we have examined the changes in the electronic structure of the pure internetallic due to the metal-hydrogen interactions when $\mathrm{H}$ is incorporated into the NiTi lattice. All the calculations are of extended Hïckel (EH) type, ${ }^{12}$ using the tight-binding method ${ }^{13}$ The parameters are listed in Table 1 .

We report the electronic and bonding structures of $\mathrm{NiTi}$ alloy with the $\mathrm{CsCl}$-type structure. The effect of incorporating $\mathrm{H}$ as an impurity on the $\mathrm{Ni}-\mathrm{Ni}$. Ti-Ti. and $\mathrm{Ni}-\mathrm{Ti}$
Table 1. Estended Hückel Parameters ${ }^{15}$

\begin{tabular}{ccccccc}
\hline atom & orbital & $\mathrm{H}_{\mathrm{ui}}(\mathrm{eV})$ & $\zeta_{1}^{a}$ & $\mathrm{C}_{1}{ }^{a}$ & $\zeta_{2}$ & $\mathrm{C}_{2}$ \\
\hline $\mathrm{Ti}$ & $4 \mathrm{~s}$ & -6.3 & 1.50 & & & \\
& $4 \mathrm{p}$ & -3.2 & 1.50 & & & \\
& $3 \mathrm{~d}$ & -5.9 & 4.55 & 0.4206 & 1.40 & 0.7839 \\
$\mathrm{Ni}$ & $4 \mathrm{~s}$ & -7.8 & 2.10 & & & \\
& $4 \mathrm{p}$ & -3.7 & 2.10 & & & \\
& $3 \mathrm{~d}$ & -9.9 & 5.75 & 0.5683 & 2.00 & 0.6292 \\
$\mathrm{H}$ & $\mathrm{ls}$ & -1.3 .6 & 1.30 & & & \\
\hline
\end{tabular}

Exponents and coeffricients in a double- $\zeta$ expansion of the $3 \mathrm{~d}$ orbital.

bonding is also analyzed with aid of density of states (DOS) and crystal orbital overlap population (COOP). Within the formalism of simple perturbation theory the interaction of two levels. $\Delta \mathrm{E}$. is given by eq. (1) ${ }^{14}$ The magnitude of the matrix element $\mathrm{H}_{31}$ in the numerator is related to the overlap of the relevant orbitals.

$$
\Delta E=\left|H_{i j}\right| /\left(E_{j o}-E_{j u}\right)
$$

and the denominator tells us that the interaction is greater the closer in energy the two orbitals are. The consequence of orbital interactions between the metal band and the hydrogen orbital can be traced down and analyzed by examining DOS curves. Contributions or projections of specific orbitals are particularly helpful. A COOP curve allows us to determine if a collection of energy levels contributes to bonding or antibonding between two atoms. In other words the COOP is indicative of the nature and the strength of a particular interatomic interaction within the unit cell. We find that both the DOS and COOP curves, in particular their combination. are very effective in analyzing the bonding properties of solid lattice. The use of these tools will be demonstrated throughout the paper. The electronic charge distribution is analyzed by means of Mulliken population analysis. The main purpose of this work is to obtain more insight into a qualitative bonding picture of interstitial hydrogen within NiTi. considering that the $\mathrm{EH}$ method can provide more detailed information regarding electronic properties of the system under investigation. 


\section{Crystal Structure}

The high temiperature phase of unhydrided NiTi alloy has a cubic $\mathrm{CsCl}$ structure with the unit-cell dimension a $=2.998$ $\AA$. The structural investigations of hydrides of $\mathrm{NiTi}$ indicate that only a few of the $16 \mathrm{Ti}$ atoms in the tetragonal unit cell are very slightly shifted from their ideal positions in the cubic $\mathrm{CsCl}$ structure of pure $\mathrm{NiTi}$. while the $\mathrm{Ni}$ atoms are much more displaced. This would correspond to a slightly expanded NiTi lattice (parameters $a=6.216 \AA$ and $c=$ $12.326 \mathrm{~A})$ due to the absorption of hydrogen in the cubic unit cell. which is about $10.5 \%$ expansion in the volume. The hydrides do not present any structural phase transition as a function of temperature. in contrast to the parent alloy $\mathrm{NiTi}$. The crystal space group is $\mathrm{I} 4 \mathrm{\textrm {mm } m}$.

The $\mathrm{H}$ atoms are located at two different octahedral sites $\mathrm{Hl}$ and $\mathrm{H} 2$ which are coordinated with two $\mathrm{Ni}$ and four $\mathrm{Ti}$ atoms. The hydrogen atoms in $\mathrm{Hl}$ sites occupy preferably the $16 n$ sites in the crystal lattice with the space group I4/ mmmm. This site corresponds to the central site of the octahedron. the comers of which are occupied by four Ti atoms and two $\mathrm{Ni}$ atoms. The octahedra that coordinate $\mathrm{Hl}$ are formed by four titanium atoms with $\mathrm{Ti}-\mathrm{H}$ distances in the range of $2.11-2.25 \mathrm{~A}$ and two nickel atoms with $\mathrm{Ni}-\mathrm{H}$ distances of $1.78 \mathrm{~A}$ (see Scheme 1). As shown in Scheme 1. this hydrogenated cluster model is constructed on the basis of the crystal structure of $\mathrm{NiTiH}$. The interatomic distances between atoms in the cluster are listed in Table 2. We perform molecular orbital calculations on this cluster to examine how hydrogen ls level is affected by its surrounding metal atoms. As a first approach to the calculations of the electronic band structure of NiTi hy'drides we have assumed a full occupancy of the H1 sites leading to a maximum content of an $\mathrm{H}$ atom per formula unit. that is. making the stoichiometry $\mathrm{NiTiH}$. since two $\mathrm{H} 2$ positions are at too short a distance to be occupied simultaneously. This simplifying assumption leads us to consider a unit cell which contains 16 formula units of $\mathrm{NiTiH}$. The tetragonal structure of NiTiH used in the calculations is represented in Figure 1.

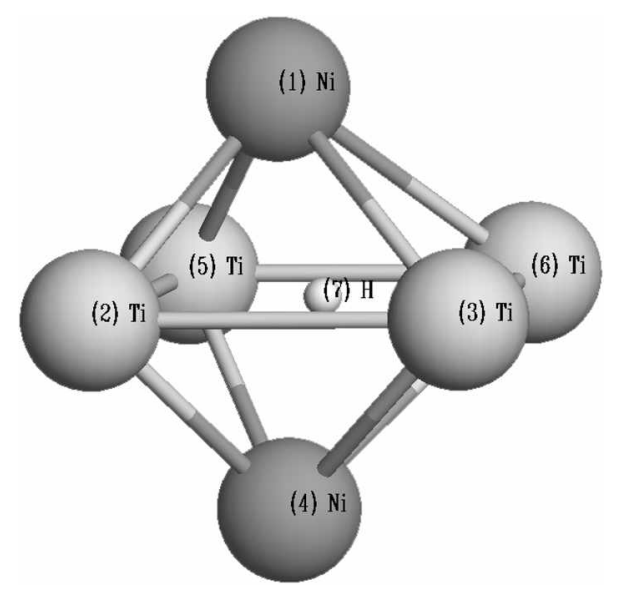

Scheme 1
Table 2. List of interatomic distances in $\mathrm{HM}_{0}(\hat{A})$

\begin{tabular}{llllllll}
\hline Atom & $\mathrm{Ni}(1)$ & $\mathrm{Ti}(2)$ & $\mathrm{Ti}(3)$ & $\mathrm{Ni}(4)$ & $\mathrm{Ti}(5)$ & $\mathrm{Ti}(6)$ & $\mathrm{H}(7)$ \\
\hline $\mathrm{N}_{1}(1)$ & 2.594 & 2.810 & 3.494 & 2.722 & 3.016 & 1.781 \\
$\mathrm{~T}_{1}(2)$ & & & 3.081 & 2.594 & 3.115 & 4.376 & 2.254 \\
$\mathrm{~T}_{1}(3)$ & & & & 2.810 & 4.231 & 3.108 & 2.107 \\
$\mathrm{Ni}(4)$ & & & & & 2.722 & 3.016 & 1.781 \\
$\mathrm{~T}(5)$ & & & & & & 2.871 & 2.124 \\
$\mathrm{~T}(6)$ & & & & & & & 2.125 \\
\hline
\end{tabular}

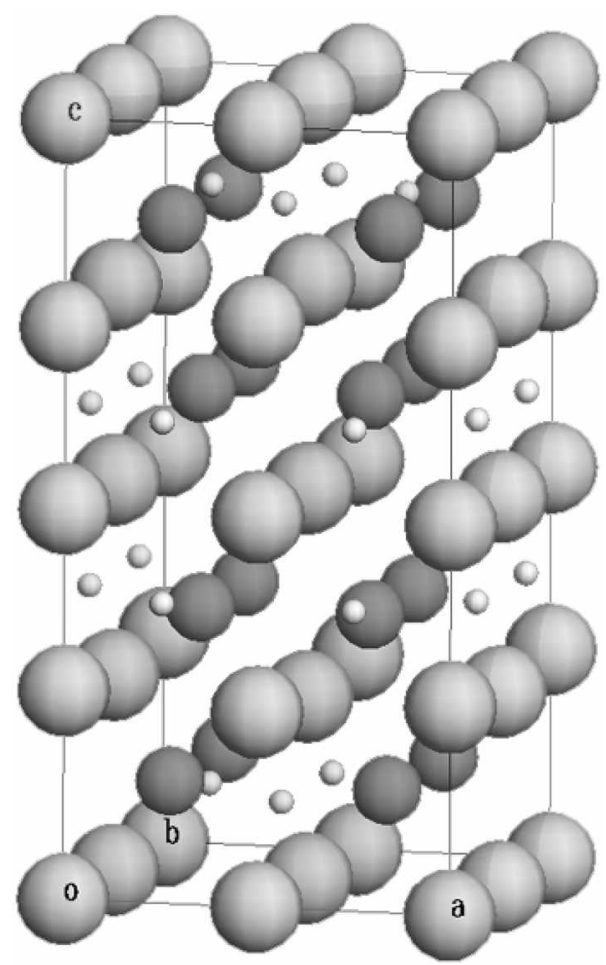

Figure 1. Structure of $\mathrm{NiTH}$. The large circles represent $\mathrm{Ti}$, the dark medium circles $\mathrm{Ni}$, and the small circles $\mathrm{H}$ atoms.

\section{Results and Discussion}

Electronic structure of NiTi. Let us first discuss the electronic structure of pure NiTi alloy. Figure 2 shows the total and projected DOS curves calculated for the cubic $\mathrm{CsCl}$ phase of NiTi. In the DOS of the bulk 3D solid the major contribution of the $\mathrm{Nid}$ states is found at low energies. the main peak corresponds to rather localized states situated between -11 and $-9 \mathrm{eV}$, while the main contribution of the $\mathrm{Ti} \mathrm{d}$ states. which are more delocalized. result in a broad structure located at higher energies between -7 and $-3 \mathrm{eV}$. A substantial number of $s$ and $p$ states penetrate the $d$ bands. The $\mathrm{d}$ band dispersion of $\mathrm{Ni}$ is much smaller than that of $\mathrm{Ti}$. reflecting the more contracted nature of the $\mathrm{Nid}$ orbital. As is typical for electron poor compounds. the Fermi level resides at low-energy part of the conduction band composed in this case mostly of Ti d orbitals. with some contribution from $\mathrm{Ni}$ orbitals. The existence of a Ti contribution to the narrow $3 \mathrm{~d} \mathrm{Ni}$ band shows covalent mixing of the Ti orbitals with the $\mathrm{Ni}$ orbitals. If we look at the detailed composition of 


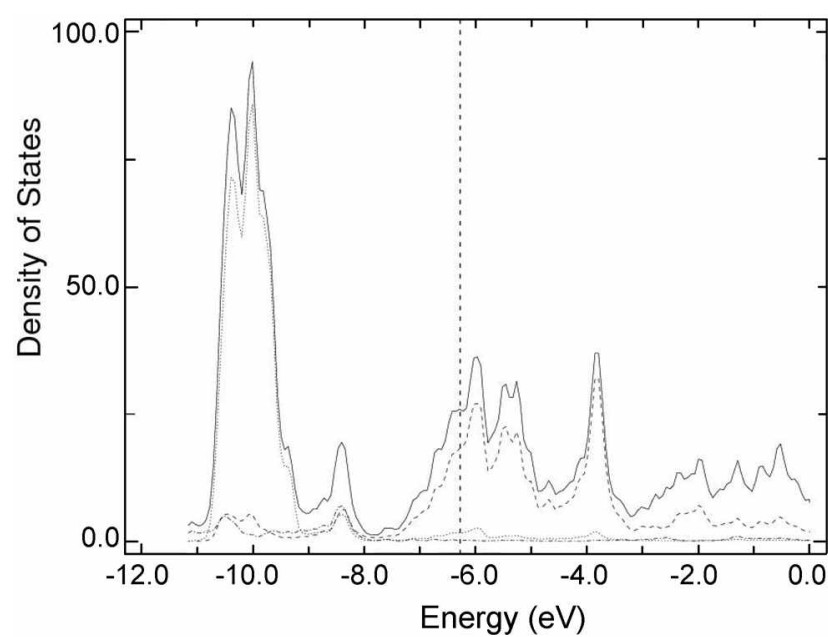

Figure 2. Total and projected densities of states for the CsCl-type structure of NiTi. Vertical line represents the Fermi level. Solid line is total DOS: dotted line is $\mathrm{Ni}$ d contribution, dashed line $\mathrm{Ti} \mathrm{d}$ contribution, and dash-dot line shows the $\mathrm{Ni}$ s contribution

the $\mathrm{Ni}$ atoms in the unit cell, we obtain the orbital population $\mathrm{d}^{9.11} \mathrm{~s}^{1.1 .06} \mathrm{p}^{\mathrm{i} .38}$. Note that on average any $\mathrm{Ni}$ atom has its $\mathrm{s}$ band approximately $1 / 2$ filled. In the case of Ti the value for the orbital population is $\mathrm{d}^{2.17} \mathrm{~s}^{6.65} \mathrm{p}^{\mathrm{j} .23}$. The $\mathrm{Ni}$ atoms are negatively charged with respect to the Ti. It is useful to remember that when two metals with different Fermi energies are placed in contact. electrons will flow from the metal with higher Fenmi energy to the metal with a lower Fermi level. This means that the electron transfer from more electropositive $\mathrm{Ti}$ atoms takes place toward the $\mathrm{Ni}$ atoms.

Regarding the bonding. COOP analysis gives additional insights related to the bond and its strength. The COOP curves of the Ti-Ti. Ni-Ti, and Ni-Ni interactions are shown in Figure 3. In both $\mathrm{Ni}$ and $\mathrm{Ti}$ metals the bottom of the $\mathrm{d}$ band is metal-metal bonding and the top metal-metal antibonding. For the majority of the COOP for the Ni-Ti bonding the Fermi level is situated slightly below empty

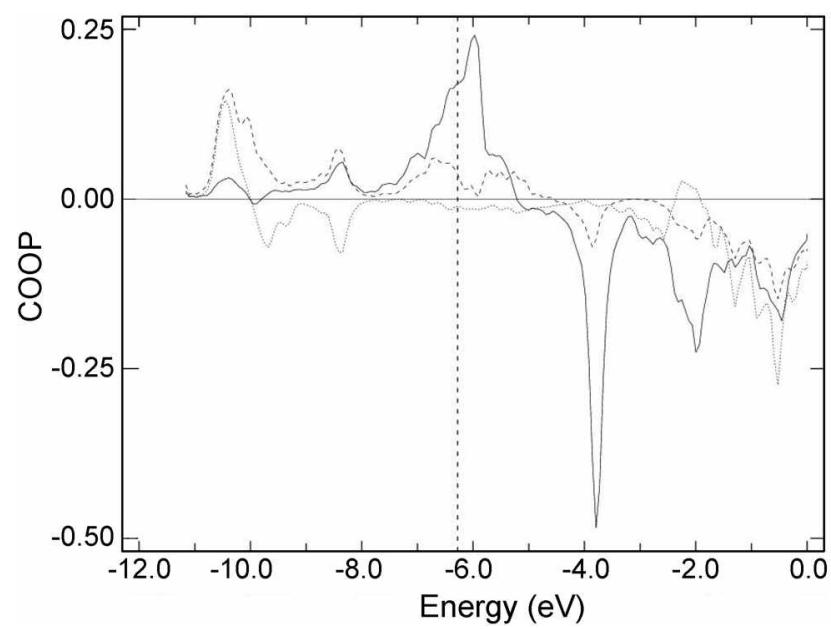

Figure 3. COOP curves for the $\mathrm{CsCl}$-type structure of NiTi. Interactions in the upper part are bonding $(+)$, in the lower part antibonding (-). Solid line is $\mathrm{Ti}-\mathrm{Ti}$ interaction, dotted line $\mathrm{Ni}-\mathrm{Ni}$ interaction, and dashed line $\mathrm{Ni}$-Ti interaction. antibonding levels: consequently these corresponding bonds are very strong and therefore responsible for the stability of the structure. The Ti-Ti interactions are bonding until -5.3 $\mathrm{eV}$. The Ti-Ti bonds also contribute significantly to the region at the Fermi level. However the net overlap population (OP) for $\mathrm{Ni}-\mathrm{Ni}$ bonds falls slightly into negative region. making these bonds least stable in the structure. The calculated $\mathrm{Ni}-\mathrm{Ti}$ OP value $(0.226)$ is much higher than that of $\mathrm{Ti}-\mathrm{Ti}(0.163)$ and $\mathrm{Ni}-\mathrm{Ni}(-0.010)$ bonds. The Ni-Ti interaction seems to be strongly bonding.

The effect of interstitial $\mathbf{H}$ on the electronic structure of NiTi. The hydrogen absorption in NiTi alloys is a favorable process. As explained earlier, the crystal lattice of $\mathrm{NiTi}$ expands by the hydrogenation. It is stressed here that in this system. any substantial changes of the crystal structure do not occur during the hydrogenation except for the onset of lattice expansion and distortion. In other words. the hydride structure is the derivative one of the parent compound. and hydrogen atoms occupy a part of the octahedral interstitial sites in the crystal lattice of the compound. For the $\mathrm{NiTiH}$ tetragonal stnucture the binding energy of $5.27 \mathrm{eV}$ per

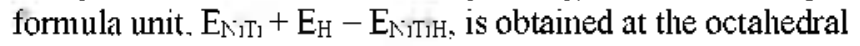
$\mathrm{H1}$ interstitial site. It is therefore of great interest to investigate how the chemical bonding between atoms in $\mathrm{NiTi}$ is modified by hydrogen incorporation. So further calculations are carried out in the following two cases by using the crystal structure shown in Figure 1.

The first case is the calculation for pure NiTi structure without any hydrogen atoms. In Table 3. this case is denoted as NiTi (expansion). The second case is the calculation for NiTi hydride with hydrogen atoms. Needless to say lattice expansion induced by hydrogenation is counted explicitly in these calculations. This is done to see only the electronic effect of interstitial hydrogen on the bond strength changes in the NiTi hydride. The DOS and COOP curves for the first case are shown in Figures 4 and 5, respectively. They show the similarities to those for the CsCl-type structure of NiTi. We have found no a significant difference in their electronic structures. The Ni orbital composition is $\mathrm{d}^{9.52} \mathrm{~s}^{1.16} \mathrm{p}^{4.35}$ whereas for Ti the composition is $\mathrm{d}^{2.16} \mathrm{~s}^{0.66} \mathrm{p}^{41.24}$. The resulting Fermi energy' is calculated to be $-6.41 \mathrm{eV}$. Both metalmetal overlap populations. $\mathrm{Ni}-\mathrm{Ti}$ and $\mathrm{Ti}-\mathrm{Ti}$. are 0.204 and 0.171 . respectively. The $\mathrm{Ni}-\mathrm{Ni}$ interaction appears to be nonbonding $(\mathrm{OP}=0.026)$.

As a good starting point for the analysis of the second case. we need to perform the molecular orbital calculations on $\mathrm{HM}_{6}\left(\mathrm{M}_{6}=\mathrm{Ti}_{4} \mathrm{Ni}_{2}\right)$ octahedral cluster to examine how both the $\mathrm{Ti}-\mathrm{Ni}$ and $\mathrm{Ti}-\mathrm{Ti}$ interactions which are strong enough to hold the metal framework are affected by the metal-hydrogen bonding. Shown in Figure 6 is the schematic interaction diagram for $\mathrm{HM}_{6}$ cluster (Scheme 1) built from the crystal structure of NiTiH. At infinite separation both the metal framework and the hydrogen are neutral. The hydrogen ls orbital at $-13.6 \mathrm{eV}$ is singly occupied. For the composite system $\mathrm{HM}_{5}$, the lowest energy level at $-14.8 \mathrm{eV}$ is the hydrogen bonding level resulting from a strong interaction between $1 \mathrm{~s}(\mathrm{H})$ and the orbitals near the bottom of the $d$ 
Table 3. Electron density, overlap population (OP), charge, and distances for NiTH tetragonal structure

\begin{tabular}{|c|c|c|c|c|c|c|c|c|}
\hline \multirow{2}{*}{ Structure } & \multirow{2}{*}{ Atom or bond } & \multicolumn{3}{|c|}{ Electron denisity } & \multirow{2}{*}{ Charge } & \multirow{2}{*}{$\mathrm{OP}^{a}$} & \multirow{2}{*}{$\begin{array}{c}\text { Distance } \\
(\AA)\end{array}$} & \multirow{2}{*}{$\begin{array}{c}\mathrm{E}_{\mathrm{F}} \\
(\mathrm{eV})\end{array}$} \\
\hline & & s & $p$ & $\mathrm{~d}$ & & & & \\
\hline \multirow[t]{4}{*}{$\mathrm{NiTi}$} & & & & & & & & -6.28 \\
\hline & $\mathrm{Ni}$ & 1.06 & 0.38 & 9.51 & -0.95 & -0.010 & 2.998 & \\
\hline & $\mathrm{Ti}$ & 0.65 & 0.23 & 2.17 & 0.95 & 0.163 & 2.998 & \\
\hline & $\mathrm{N}_{\mathbf{l}}-\mathrm{Ii}$ & & & & & 0.226 & 2596 & \\
\hline \multirow[t]{4}{*}{ NiTi(exp) } & & & & & & & & -6.41 \\
\hline & $\mathrm{Ni}$ & 1.06 & 0.35 & 9.53 & -0.92 & 0.026 & $2.72-2.76$ & \\
\hline & $\mathrm{Ti}$ & 0.66 & 0.24 & 2.16 & $0.18-1.19$ & 0.171 & $2.87-3.29$ & \\
\hline & $\mathrm{Ni}-\mathrm{Ti}$ & & & & & 0.204 & $2.48-3.02$ & \\
\hline \multirow[t]{7}{*}{$\mathrm{NiTiH}$} & & & & & & & & -6.37 \\
\hline & $\mathrm{H}$ & 1.53 & & & -0.53 & & & \\
\hline & $\mathrm{Ni}$ & 0.89 & 0.38 & 9.52 & -0.77 & 0.004 & $2.72-2.76$ & \\
\hline & $\mathrm{Ti}$ & 0.47 & 0.21 & 2.02 & $0.65-1.68$ & 0.126 & $2.87-3.29$ & \\
\hline & $\mathrm{Ni}-\mathrm{Ti}$ & & & & & 0.160 & $2.48-3.02$ & \\
\hline & $\mathrm{H}-\mathrm{Ti}$ & & & & & 0.103 & $2.11-2.25$ & \\
\hline & $\mathrm{H}-\mathrm{Ni}$ & & & & & 0.102 & 1.781 & \\
\hline
\end{tabular}

Arerage value.

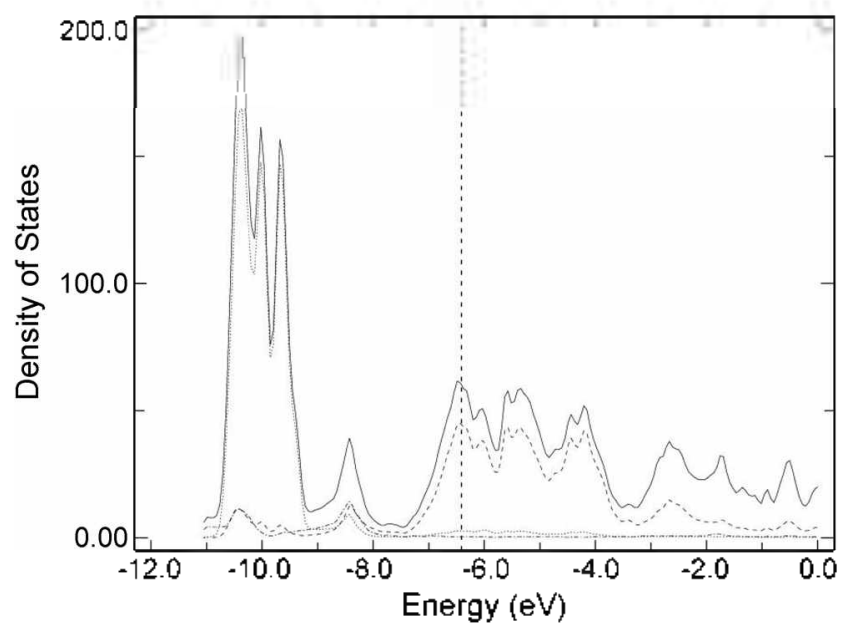

Figure 4. DOS curves for NiTi sublattice after $\mathrm{H}$ absorption. Vertical line represents the Fenni level. Solid line is total DOS: dotted line is Ni d contribution, dashed line Ti d contribution, and dash-dot line shows the Ni s contribution.

band corresponding basically to the " $a_{1}$ " orbital expected for an approximately octahedral metal ligand framework $\left(\mathrm{M}_{6}\right)$. The metal orbitals of $\mathrm{M}_{6}$ interact strongly with each other, creating relatively wide $s$ and $d$ bands. Some of the $\mathrm{M}_{6}$ framework levels are M-M bonding, some nonbonding. and some antibonding. Thus, the hydrogen atom mainly interacts with some of the low-lying M-M bonding levels to give filled $\mathrm{M}-\mathrm{H}$ bonding and mostly empty antibonding combinations and a strong hydrogen-to-metal bond is developed with both $\mathrm{Ni}$ and $\mathrm{Ti}$ atoms in $\mathrm{HM}_{6}$. The interaction of hydrogen with bonding combinations of the metal orbitals results in a delocalization of the charge in these orbitals into metal-to-lydrogen bonds. and hence a loss of metal-to-metal bonding.

We proceed now to explore the interaction of hydrogen ls orbital with the metal bands in the 3D NiTiH solid. The addition of an $\mathrm{H}$ atom at the center of the metal octahedron

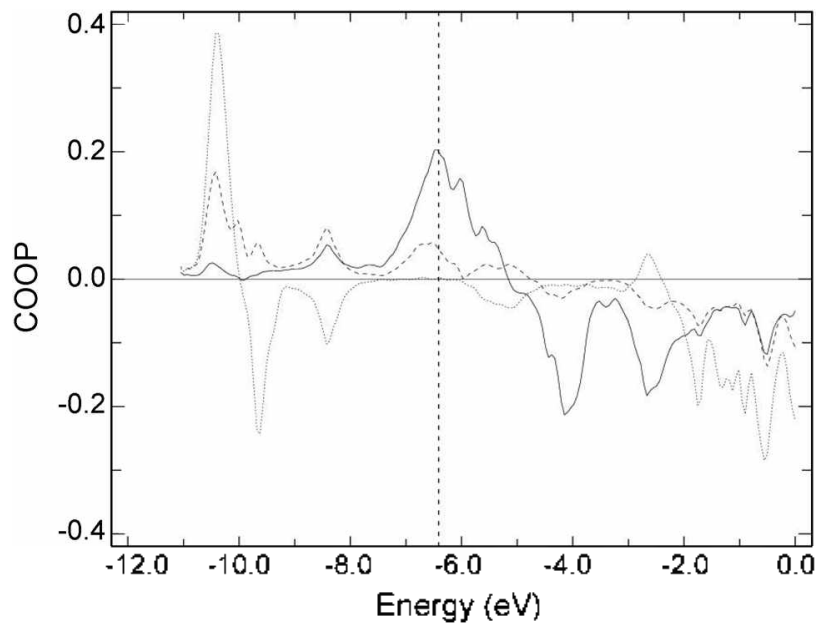

Figure 5. COOP curves for NiTi sublattice after $\mathrm{H}$ absorption Interactions in the upper part are bonding $(+)$, in the lower part antibonding (-). Solid line is $\mathrm{Ti}-\mathrm{Ti}$ interaction, dotted line $\mathrm{Ni}-\mathrm{Ni}$ interaction, and dashed line Ni-Ti interaction.

described earlier pushes the metal states slightly up in energy: but also takes away from the host lattice one electron. These two effects almost cancel each other. Thus, the Fermi level remains at the same position (raised by about $0.04 \mathrm{eV}$. see Figure 7) upon the addition of the interstitial $\mathrm{H}$. We can trace the validity of the perturbation theory based characterization of the primary interactions by examining the consequences of interaction in the DOS curves in Figure 7. Projection of the hydrogen ls orbital is represented by dotted lines and the position of this orbital in the isolated hydrogen by an arrow. As expected. the energy of the hydrogen 1s orbital changes significantly upon interaction with the metal orbitals. We observe the presence of a structure at low energy. centered at about $-14.8 \mathrm{eV}$. which results from the metal-hydrogen bonding. The ls band is pulled down to a lower energy by $\sim 1.2 \mathrm{eV}$. The large shift of this band relative to the ls orbital $(-13.6 \mathrm{eV})$ of the isolated hydrogen is a clear indication of 


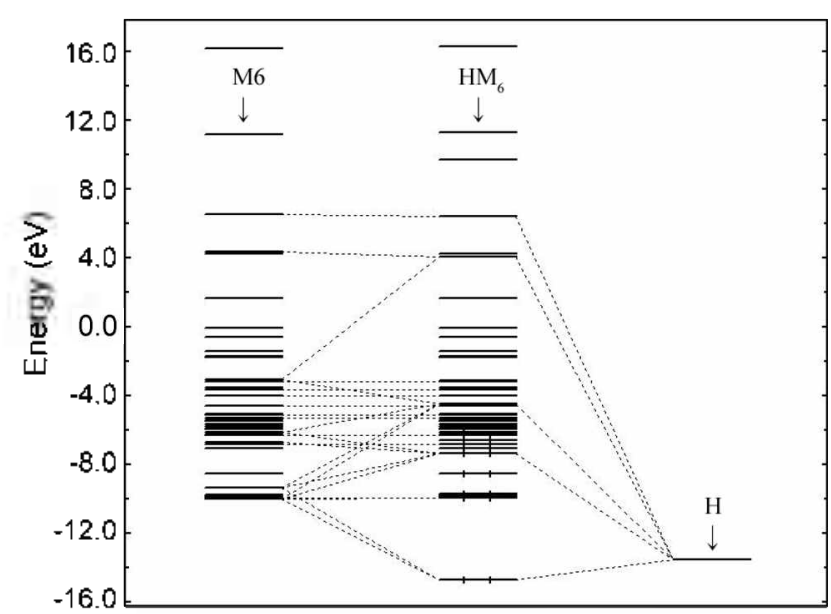

Figure 6. Schematic interaction diagram for $\mathrm{HM}_{\phi}$ cluster (Scheme 1) built from the crystal structure of $\mathrm{NiTiH}$.

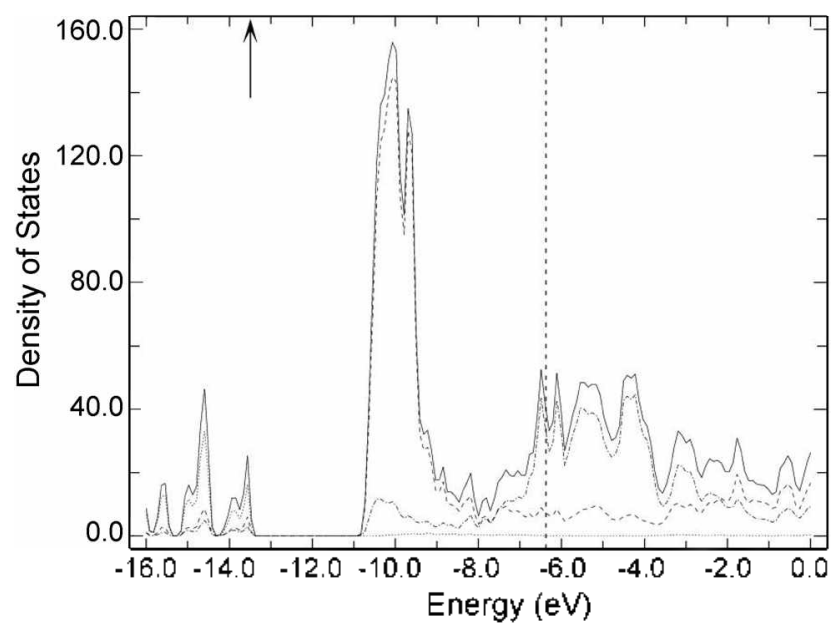

Figure 7. DOS curves for the NiTiH structure: total DOS (solid line), projected $\mathrm{DOS}$ on $\mathrm{H}$ (dotted line), $\mathrm{Ni}$ (dashed line), and $\mathrm{Ti}$ (dash-dot line). The arrow indicates the $\mathrm{H}$ Is energy before interaction.

its strong interaction with the metal. It is interesting to note that the $\mathrm{Ni} d$ contribution is larger than the Ti $\mathrm{d}$ contribution in the low-lying structure of the DOS: the larger interaction of $\mathrm{H}$ ls with nickel states is due to the energy position of $\mathrm{H}$ ls closer to the $\mathrm{Ni} d$ than to the $\mathrm{Ti} d$ band. The interaction. of course. depends on the shorter $\mathrm{Ni}-\mathrm{H}$ distances. The DOS curves in Figure 7 are calculated for the choice of the M-H distance in Table 2. Figure 7 looks similar to that of the $\mathrm{NiTi}$ lattice without $\mathrm{H}$ (Figure 4). except for the 1s band. The orbitals at the bottom of a metal band are metal-metal bonding. those in the middle nonbonding. and those at the top antibonding. What we can say is that ls interacts more strongly with the bottom of the metal $\mathrm{d}$ band than with the top. judging by the interaction diagram in Figure 6. In analogy to discrete complexes we focus our attention on locally strong $\sigma$ interactions. In addition to d. s orbitals have the proper local symmetry to interact. ls does not interact with a given level but interacts more (or less) with such and such part of a band. 1s is pushed down in energy and its
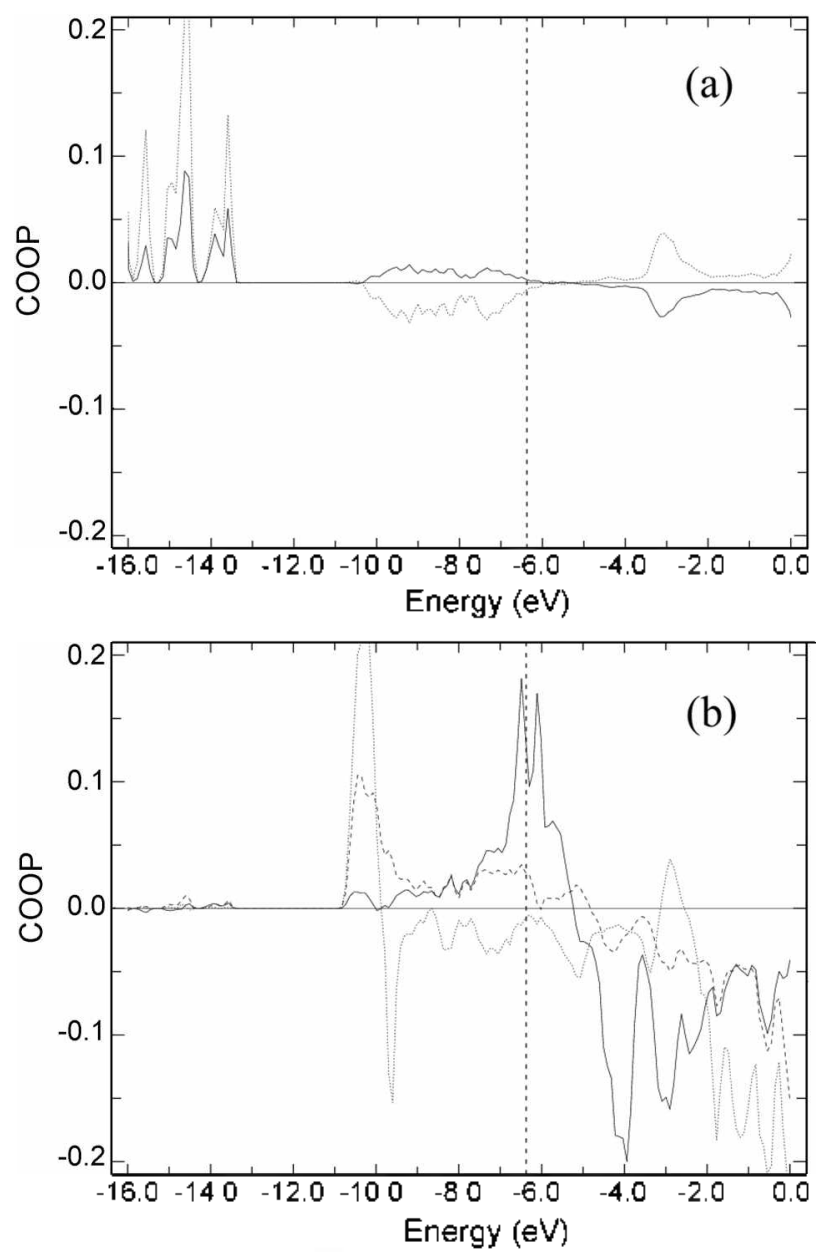

Figure 8. COOP curves for the NiTiH structure: (a) Ti-H (solid line) and $\mathrm{Ni}-\mathrm{H}$ (dotted line); (b) Ti-Ti (solid line), Ni-Ni (dotted line), and $\mathrm{Ni}-\mathrm{Ti}$ (dashed line).

bonding partners in the metal $\mathrm{d}$ band region are characterized by weak Ni-H antibonding and $\mathrm{Ti}-\mathrm{H}$ nonbonding. This is shown in Figure 7, along with the COOP curves of Figure 8. The three DOS peaks in the region of -13.5 to -16 $\mathrm{eV}$ are made up mostly of hydrogen ls states which are stabilized by interaction with the bonding orbitals of metal d and $\mathrm{s}$.

This is attested to by the contribution of these orbitals (see projections in Figure 7 ) and their predoninant metal-hydrogen and metal-metal bonding character (see the COOP curves in Figure 8). The antibonding component of the metalhydrogen interaction spreads over a relatively wide energy range. but the strong one appears at the range of about 1 to $15 \mathrm{eV}$ which is not shown in this figure. Many of the states in it are pushed up above the Fermi level. The COOP curve shows a highly delocalized antibonding region of $\mathrm{Ni}-\mathrm{H}$ from -10 to $-6 \mathrm{eV}$ and $\mathrm{Ti}-\mathrm{H}$ from -4 to $\mathrm{leV}$. The still higher energy $\mathrm{M}-\mathrm{H}$ antibonding region arises from out-of-phase mixing of metal $\mathrm{s}$ and $\mathrm{p}$ with hydrogen $1 \mathrm{~s}$. The hydrogen is bound to the metal primarily by the ls-d. s interaction. It is clear that the ls bonding state is fully occupied and its antibonding combination is mostly unoccupied. Note that this brings the $\mathrm{H}$ atom closer to $\mathrm{H}^{-}$. The Is band is sub- 
stantially more than half populated, with 1.53 electrons per hydrogen atom (see Table 3). Interaction of hydrogen with unfilled metal band states might reverse charge transfer to metal. But the calculations show no signs of that interaction that is not very effective. since the separation in energy' between the interacting orbitals is large. The states around the Fermi level contribute invariably to strong Ti-Ti bonding. Whereas the $3 \mathrm{~d}$ states of nickel are located in a sharp peaks around $-10 \mathrm{eV}$ those of $\mathrm{Ti}$ are extended broadly from ca. $-7 \mathrm{eV}$ up to well above the Fermi level of $-3 \mathrm{eV}$. It is concluded that $\mathrm{Ni} \mathrm{d}$ orbitals are more or less completely filled and the $\mathrm{H}$ ls states are substantially populated. whereas the Ti $\mathrm{d}$ states are partly occupied.

We now turn to the metal-metal bonding changes upon absorption of the hydrogen atoms. as measured by the overlap population. The overlap population of electrons between atoms is a measure of the strength of the covalent bond between them. We find in Table 3 that as the new M-H bond is formed the metal-metal bonds around the binding site are weakened. Thus. the average overlap population (OP) between $\mathrm{Ni}$ and $\mathrm{Ti}$ drops from 0.204 in the pure NiTi alloy to 0.160 in the NiTi hydride (similarly for $\mathrm{Ni}-\mathrm{Ni}$ and $\mathrm{Ti}-\mathrm{Ti}$ the values are 0.026 and $0.004,0.171$ and 0.126 . respectively'). Thus the hydrogen-metal interactions greatly modify the bond strengths between $\mathrm{Ti}$ atoms or between $\mathrm{Ti}$ and $\mathrm{Ni}$ atoms. all of which neighbor on the hydrogen atom. To some extent the new $\mathrm{M}-\mathrm{H}$ bond (with the respective $\mathrm{OP}$ values of 0.102 and 0.103 for $\mathrm{Ni}-\mathrm{H}$ and $\mathrm{Ti}-\mathrm{H}$ ) is formed at the expense of weakening the M-M bonds within the metal lattice. These are competing effects. Table 3 summarizes the electron densities charges and overlap populations for selected atoms.

Further insight into the bonding mechanism is provided by analyzing the charge distributions. The ionicities of $\mathrm{Ti}$ atoms are always positive. whereas those of $\mathrm{H}$ and $\mathrm{Ni}$ atoms are always negative. This is reasonable since $\mathrm{Ti}$ is the more electropositive element than $\mathrm{H}$ and $\mathrm{Ni}$. The hydrogen is calculated to be strongly negative with a charge of -0.53 . Thus. upon absorption strong electron transfer from both metals to $\mathrm{H}$ takes place. and hence the $\mathrm{Ti}$ atom becomes more positively $(0.65-1.68)$ and $\mathrm{Ni}$ less negatively charged $(-0.77)$. In the $\mathrm{Ti}$ case the $\mathrm{d}$ band is higher in energy than that of $\mathrm{Ni}$ and should interact less effectively with $\mathrm{H}$ ls by the energy criterion of eq. (1) and lose more electrons. The electron transfer derives primarily from the large occupation of ls on $\mathrm{H}$ absorption. and that in turn is a consequence of the bonding interaction of $\mathrm{H}$ ls with the metal-metal bonding states near the bottom of $\mathrm{Ni} d$ band. the small peaks in the DOS at the region of -13.5 to $-16 \mathrm{eV}$. Both $\mathrm{Ni}$ and $\mathrm{Ti}$ metals actually lose their electron densities through this interaction. as many $\mathrm{d}$-ls antibonding combinations are pushed above the Fermi level. These results clearly indicate that the weakening of metal-metal bonds in $\mathrm{NiTiH}$ is caused by the electron transfer from metal-metal bonding orbitals to hy'drogen.

For hydrogen concentrations larger than 1 , up to the structurally investigated material $\mathrm{NiTiH}_{1.4}{ }^{6}$ the $\mathrm{H} 2$ sites are being populated substantially and this site occupancy can no longer be ignored. The small occupancy of the $\mathrm{H} 2$ sites and the consequent displacements of the metal atoms could result in some small distortion of the metal $\mathrm{d}$ bands and in some small shifts of the low energy metal-hydrogen bonding states. However, the important results of the present calculation are not expected to be significantly altered.

\section{Conclusions}

According to our calculations. the $\mathrm{H}$ absorption is a favorable process in NiTi alloy structure. The H-metal interaction is favored at the octahedral $\mathrm{Hl}$ interstitial site. The Ti-Ti and $\mathrm{Ti}-\mathrm{Ni}$ bonds neighboring on $\mathrm{H}$ are significantly weakened while $\mathrm{H}-\mathrm{Ti}$ and $\mathrm{H}-\mathrm{Ni}$ bonds are developed. A substantial charge transfer from bonding states of metal orbitals to hydrogen plays an important role in the creation of the hydrogen-metal bonds. leading to a weakening of metal-tometal bonds. The overlap population between metal atoms is considerably smaller in the hydride than in pure NiTi. The metal-hydrogen bonding interactions are crucial to the stability of the hydride.

Acknowledgment. This work was supported by the Kyungsung University Research Grant in 2006.

\section{References}

1. (a) Lee, R. N.: Withers, R. J. Appl. Phus 1978, 49, 5488. (b) Zhao. G. L.: Harmon. B. N. Plns. Rev B 1993, 48. 2031. (c) Ye. Y. Y.: Chan, C. T.: Ho, K. M. Phys. Rev $B 1997,56,3678$. (d) Rhee. J. Y: Harmon. B. N.; Lynch. D. W. Plys. Rev B 1999. 59.1878. (e) Bihlmaver. G.; Eibler. R.: Neckel. A. Phys. Rev B 1994, 50. 13113. (f) Pasturel. A.: Colinet. C.: Marth. D. N.: Paxton. A. T Phis. Rev B 1995. 52. 15176. (g) Wang. X.: Ye. Y. Y.: Chan1. C. T.: Ho. K. M.: Harmon. B. N. Phos Ren: B 1998. 58. 2964.

2. Wiswall. R. In Hydrogen in Metals II. Topics in Applied Phusics: Alefeld, G. Volk1. J.. Eds.: Springer: Berlin. 1978: Vol. 29, p 201.

3. Buchner. H; Gutjahr, M. A; Beccu, K. D.: Safferer. $H$. Z. Metalkd. 1972. 63.497.

4. Wakao. S.: Yonemura. Y: Nakano. H.: Schumada. H. J. LessContmon Het. 1984. 104. 365 .

5. Noreus, D; Werner. P. E: Alasafi. K: Schmidt-Ihn, E. $l h t . d$. Hydrogen Energu $1985,10,547$.

6. Soubeyroux. J. L.; Fruchart, D; Lorthioir, G.: Oehin. P: Colin. C. J. Allows Comp. 1993. 196. 127.

7. Eibler. R.: Redinger. J.: Neckel. A. J. Phws. F: Met. Phus. 1987. 17. 1533.

8. Sanati, M.: Albers, R. C.: Pinski, F. J. Phos Rev B 1998. 58.13590.

9. Nambu. T.: Ezaki. H.: Yukawa. H.: Morinaga. M. J. Allous Contp. 1999. 293-295.213

10. Kellou. A.: Nabi. Z: Tadjer. A.: Amrane. N.: Fenineche. N.: Aourag. H. Phys. Stat. Sol. B 2003. 239.389.

11. Gupta. M.: Rodriguez. E. J. Allow Comp. 1995. 219.6.

12. Hoftmann, R. J. Chem. Plys. 1963. 39. 1397.

13. (a) Whangbo, M.-H.: Hoffmann, R. J.Am. Chem. Soc. 1978. 100. 6093. (b) Whangbo, M.-H.; Hottmann. R.: Woodward, R. B. Proc. R. Soc. London 1979. 1366. 23.

14. Hoftimann. R. Solids and Surfaces: A Chentist's Iiew of Bonding in Extended Sintctures: VCH Publishers: New York. 1988.

15. Alvarez. S. Tables of Parameters for Extended Hückel Calculations: Barcelona, Spain, 1995. 